\title{
Academic Achievement of college students based on Co- curricular Activities
}

\author{
Laraib $^{1 *}$, Abdul Sami ${ }^{2}$, Asmara Irfan ${ }^{3}$ \\ ${ }^{1}$ Department of Business Administration, University of the Punjab, Jhelum Campus, Jhelum, Pakistan \\ ${ }^{2}$ Department of Management Sciences, University of Jhang, Jhang, Pakistan \\ ${ }^{3}$ Azman Hashim International Business School, Universiti Teknologi Malaysia, Malaysia
}

*Corresponding Author: Laraib, Department of Business Administration, University of the Punjab, Jhelum Campus, Jhelum, Pakistan. laraibt171@gmail.com

\begin{abstract}
The purpose of this study is to find out the relationship between Co-curricular activities and Academic Achievement. Co-curricular activities also helpful for the benefit of country. There are many benefits of co-curricular activities for students it includes, self-confidence, better communication skills, improves physical and mental abilities. Qunantative method of survey is used for this research Data is collected from almost 400 students of different colleges from both genders. With the help of analysis there are positive relationship between Co-curricular activities and Academic Achievement. From results of this research the government and education institutes have to play a very strong part. Government should provide proper resources, finance and a plate-form on which students can show their abilities. Educational institutes also focus on co-curricular activities rather than to get just high score and motivate them. Students will concentrate on co-curricular activities according to the quickest shift in technology to high academic achievement
\end{abstract}

Keywords: Co-Curricular Activities, Academic Achievement.

\section{INTRODUCTION}

The purpose of this research is to prove that Co-curriular Ativities are important for Acadamic Achivement. Collages are a social organization in which principle, teachers and student have common involvement in the Co-curricular activities for the benefit of pupils. The goals of the collages are identified on the grounds of organizational attempts of those who discover.

Co-curricular activities encourage passion, strength, self improvement and team cohesion that add to the growth of character. Co-curricular activities create different fields of mind and character, including mental and social growth, moral and esthetical growth.

Collages provide all learners with higher education, regardless of race and religion. Pupils from different walks of life must not atmosphere depressed in collage only at that stage in their life. To be trained, all of them would have access to education. Having this type of environment, needs proper planning. Effective collages improve teachers learning process. 
Society expects their kids to receive standard education. The scheme of collage should guarantee the general growth of a student. He should not only have one qualification to join the profession, but he should also provide serving abilities that allow him to be a helpful community member and play an efficient part in the country's growth. The impressive collages fulfill educational expectations of parents. Both learners and educators in such collages are working hard to fulfill society's desires, while professors and students in less efficient classrooms do not experience such disturbance.

In an exceptional collage, there is a prevalent cause among the population, with the exception of the chairman, educators and pupils. There is a prevalent cause among the population, with the exception of the chairman, educators and pupils. They are easily acknowledged for their private and environmental accomplishments. Effective collage performance does not depend solely on a regular high morality variable, high student achievement or good passing ratio, but is the net result of all this and more.

\section{LITERATURE REVIEW:}

\section{CO-CURRICULAR ACTIVITIES}

According to Balls (2008) Excellent teaching and learning is the unique contribution of good collages that helps kids create confidence, learn about teamwork, management accountability and successful interactions. Collages could provide more possibilities for kids and their families to take part in sports and cultural operations as an essential community resource. Good collages have the knowledge of a student. The education systems of the Pakistani Government allow learners to foster their hidden talents and abilities, making it easy for them to play an efficient part in society's growth. In order to understand their culture and history, education should instil in them the patriotism and personality-building spirit, the quality of tolerance, social justice and democracy. They ought to be well conscious of the ideology of Pakistan.

A 2006 research undertaken that identified the most significant learning goal and reported that it was to enable an individual to develop their inner characteristics. While teachers were asked, On the other side, remember the prior understanding of the communicator. The study also indicated instructor should conduct a variety of classroom activities to build a good college environment by communicator and fixing the psychological and Sentimental difficulties of a student that a professor can produce effective teaching.

Hanson (2000) Documented: Collages also have their own distinctive cultures formed by a Specific blend of values, convictions and craving. These college environments highlight what is Significance as they seeking to create their skill set in a specific dimension, such as generating excellent cricket teams, high scores, Structured courses and qualified technicians, or sending children to college from urban collages. Despite the environment of a collage is not noticeable to the human sight, it reflects particular cultural objectives in its artefacts and symbols. The accepted element of educational management was to give peace of mind to the students.

The School Leadership Act's 'Visibility' Act discussed itself to the point that the school leader was in touch with educators, students, and relatives and interacted with them.

Blase and Blase (1994) as reporting that routine in collages were extremely efficient teachers The suggested ' Visibility ' impact was double: first, it sent a message that the chairman was investing in the college's everyday activities Secondly, it gave the chairman the chance to communicate on important problems with educators and pupils; In meta-analysis, particular behaviours and features connected with this culpability were recognized through Systematically and frequently visits to schools; through frequently interaction with learners; and through high visibility to learners, educators and parents. 


\section{ACADEMIC ACHIEVEMENT}

Literacy plays a main role in knowledge and abilities development. It enables fashion and model people in any community to work well in their environment. A significant element of education is academic performance. Hanson (2000) noted that distinct variables, such as teaching abilities, gender and ethnicity, affect student achievement. Bhatti et al., (2018) establish the relationship of personality and academic acheivement. Simmons et al. (2005) found that the amount of family revenue, full-time participation, support and completion of sophisticated college courses had statistically significant impacts on the persistence of schools among college pupils of the first generation. Educational attainment relates to how learners handle their tests and how they handle or achieve the various duties allocated to them by their educators over a specified period or educational year (Dimbisso, 2009). The levels, marks and results allocated to educators evaluate attainment in separate topic fields (Adediwura \& Tayo, 2007). The grades and scores acquired by learners reflect students ' academic standing and also point to the efficacy of collages, decent education indicators, a main variable of the well-being of young individuals in specific and the country as a whole (Lewin, Wasanga \& Somerset, 2011). Some study discovered close ties between student academic performance and domestic growth. It has been discovered that students with elevated academic results are more efficient and add to the productivity growth of the country. At all levels of training in Bhutan, academic performance is crucial. The advancement of learners from one grade to the next is a significant criterion. Higher education is the most significant phase in learners ' lives as they are making a significant shift to higher education. Educational attainment defines how this transition is made by successful learners. Learners who want to go into high school are able to obtain admission to excellent schools and universities. Academic performance also determines the job placement of students. Students who have high academic scores in their tertiary education have more opportunities to choose their future jobs and receive higher salaries. While high academic performance has numerous positive impacts, poor academic performance may have unfortunate consequences for students, teachers and society at large. Poor academic performance at secondary school, undermines students ' likelihood of joining greater educational institutions and jeopardizes work placement possibilities and, in most instances, decreases individuals ' active involvement in domestic growth. It is an issue that is detrimental to society's excellently-being, as it hampers the soft implementation of the value of education, which are to guide the person mentally for self and society's service.

\section{RELATIONSHIP OF CO-CURRICULAR ACTIVITIES AND ACADEMIC ACHIEVEMENT}

There is a lot of Literature Review on the relationship between co-curricular activity and academic achievement. Co-curricular activities are variable and academic achievement is variable. (1870-1890) was marked as a rejection period. Educational rulers found that the development of human or material resources they label as curricular would benefit few, if any, learners. It was a period of complete rejection. Rulers found that learning experiences could be provided by student clubs and organisations. It was a time of actively adopting and promoting. In favor of student involvement, the discussion on the instructional advantages of engaging in student activities was chosen. One of these principles proposed that colleges should train learners to use their free time wisely. As a consequence, many colleges have assigned a manager to supervise the plan of academic advising. Another significant innovation in this region was the work of Columbia University's Elbert Fretwell. The movement of extracurricular activities obtained even greater credibility in 1926, when the National Society for the Study of Education (NSSE) included studying extracurricular student activities in its annual yearbook. The NSSE evaluation criteria retained that student activity was the main way to achieve goals which are not or cannot be properly served by periodic school operations. American education confronted huge financial obstacles throughout the depression of the 1930s. Schools were closed, teachers were lowered, wages were cold and severed programs. Moreover, learners' level of extracurricular involvement stayed unchanged, so these systems stayed intact. Illustrating pro-academic accomplishment, such as class job attempts, 
preparation for practice and interest in lessons, encourages student sports ' academic strength Extracurricular student activity programs have continued to play an important role in the education system over the previous three decades. It indicated that $70 \%$ of learners surveyed in high college thought it was more essential to participate in extracurricular operations than to earn high school or have a vehicle. Researchers recognized beneficial connections between extracurricular and academic involvement (according to Broh 2002). The launch of the 1957 Sputnik satellite compelled America to conduct a critical assessment of the system of social education. Although most of the other elements of U.S. government greater education at the moment were strongly monitored and altered, extracurricular student programs stayed unchanged. Ostro (2006) discussed how being part of a team sets norms that motivate learners to retain greater levels of involvement in the scholarly community. Ostro tried to argue that competitive environments that generate favourable government expectations are encouraged by colleges that perform well academically. Pupil who took part in co-curricular activities and who did not take part in those operations said that "learners who took part in extracurricular activities at college had greater grades, greater educational ambitions and better educational behaviour than those who did not take part in extracurricular activities at all. Bartkus et al. (2012) further indicated that "extracurricular activities do not require a degree or academic credit and the involvement of the student is voluntary." Knowledge in extracurricular activities has now become an important part of today's college life for several students. Many colleges have spent substantial resources in extracurricular activities and are required to provide a variety of out - of-school activities to provide balanced education. In public literature on education, the effect of involvement in extracurricular activities on pupil growth was widely analysed. A far more latest and extensive study of the extracurricular literature for college students in the United States found that while such activities are regarded to be very significant "teenage growth settings," little is recognized of the qualitative factors impacting that growth or the relationship between participation and out.

From the above discussion, we formulate our Hypothesis

$\mathbf{H 1}=$ There is relationship between Co-Curricular Activities and Academic Achievement.

\section{FRAMEWORK}

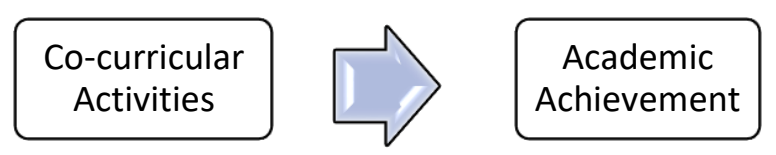

Fig. 1. Relationship between Co-Curriular Activities and Academic Achievement

\section{RESEARCH METHODLOGY}

Jhelum city have almost 30 colleges. In which 15 colleges owned by government of Punjab and 15 colleges are private. It is not possible to collect data from all the colleges. So, data is collected from Government Post graduate college and Private Punjab group of collages. Research data is collected from the co-educational institutes from BS students. The primary data is gathered through a questionnaire and the secondary data is obtained through a review of literature. The Total population of these 2 colleges are 1000 of BS students. The Research data is collected from 400 students. In which $62 \%$ are female and $38 \%$ are male and $76 \%$ are from the Age group of 18 to $22,24 \%$ are from the Age group of 23 and Above. Online Questionnaire make on Google dos. Email ids of student are collected from their colleges authority and send them email. 500 email were sent, in which 400 students give response. Questionnaire was designed with the help of different Research papers and by me on ability. There are 30 multiple choice in this questionnaire. 


\section{DATA ANALYSIS}

Demographic part contains demographic information of respondents to collect their age, gender, qualification and experience. Detail of these demographic data is illustrated in Table 1. Table 1 shows that the 152 of the respondents were male rest 248 of the respondents were female that is $38 \%$ and $62 \%$ respectively. $76 \%$ respondent's belongs to age group $16-22$ and $24 \%$ were from age group $23 \&$ above.

Table 1: Demographic Characteristics of Respondants

\begin{tabular}{lll}
\hline Demographic & Frequency & Percentage \\
\hline Gender & & \\
Males & 152 & $38 \%$ \\
Female & 248 & $62 \%$ \\
Total & & \\
Age Group & & \\
$18-22$ & 304 & $76 \%$ \\
23 \& above & 96 & $24 \%$ \\
Total & & \\
\hline
\end{tabular}

\section{Measurement Model Validation}

The current study applied SEM statistical techniques. SEM is a statistical technique to analyze the structural relationship. After fixing the indicators of the measurement PLS algorithm approach was utilized. There are two types of models in PLS analysis one is measurement model and second is structural model (Hair Jr et al., 2013) and it is considered as one of the best statistical procedures for SEM. Measurement model is used to check the construct reliability and validity and loadings of all indicators through PLS by testing the convergent and discriminant validity (Urbach and Ahlemann, 2010). After checking measurement model; structural model was used to confirm the hypothesized relationship of the study.

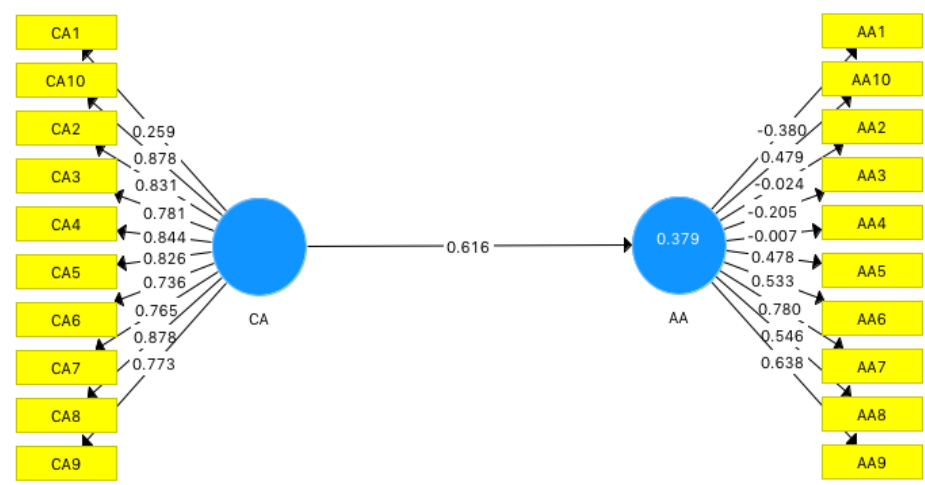

Fig. 2: Initial Measurement Model

Convergent supposed to measure the same construct and show that they are related. (Hair Jr et al., 2013; Rasli, 2006). Convergent validity deals with construct loadings, Average Variance Extracted (AVE) and constructs reliabilities.

In order to analyse the convergent validity, it is important to examine whether all the items are significantly loaded on a construct. Indicators reliability were guaranted by checking main loading and cross loading of items. The question items with the main loading value of 0.5 and above are retained suggested by Hair et al. (2013). 
The results show that $C A 1, A A 1, A A 2, A A 3, A A 4, A A 5$ and $A A 10$ were dropped in checking cross loadings. These items showed low factor loadings. At second stage, removed all those items that are less than 0.70 and creating a problem in convergent and discriminant validity. The dropped item at the second stage was AA6. Figure 2 shows the outer loading of the final measurement model.

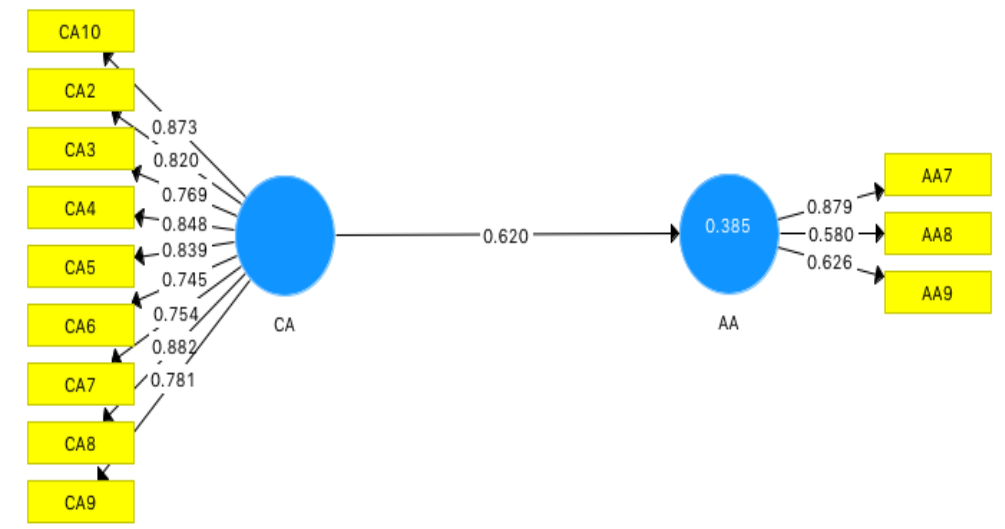

Fig. 3: Final Measurement Model

AVE is used to assess discriminant validity and is the sum of square of standardized factor loadings to represent how much variation in each item is explained by latent. In addition, AVE is the average percentage of variation described by the measurement items in a construct. The standard value of AVE is 0.50 or higher.

Table 2: Average Variance Extraction of all constructs

\begin{tabular}{ll}
\hline Constructs & Final AVE \\
\hline Cocurricular Activities & 0.662 \\
Academic Achievement & 0.500 \\
\hline
\end{tabular}

Table 2 shows that the average variance extraction of the cocuricular activities was 0.662 and academic achievement was reported 0.500.

Table 3 shows the construct reliability value of each variable. The threshold value of the Composite reliability is 0.70 or above (Sami et al., 2016). Table 3 shows that all the constructs have the adequate reliability of all constructs.

Table 3: Reliability of all Constructs

\begin{tabular}{lll}
\hline Construct & Final Cronbach's Alpha & Final Composite Reliability \\
\hline Cocurricular Activities & 0.947 & 0.946 \\
Academic Achievement & 0.592 & 0.743 \\
\hline
\end{tabular}

The composite reliability value for cocuricular activities was reported 0.946 and academic achievement was reported 0.743 . Cronbach's Alpha value for cocuricular activities was reported 0.947 and academic achievement was reported 0.592. These values indicated a high level of reliability of the instrument. Thus, based on outer loadings, AVE and construct reliabilities it can me concluded that there is no issue of the convergent validity of the constructs in the current study.

\section{Structural Model (Hypothesis Testing)}

Research hypotheses were tested through the results of structural model. The results of the hypothesis are generalized on the basis of path coefficients, p-value, and t-values, with a significance level of 0.05 . Hypothesis states that cocuricular activities has a positive relationship with academic 
achievement. Path coefficient of the cocuricular activities $\rightarrow$ academic achievement was 0.620 with R2 value $38.5 \%$, $t$ value greater than 1.96 and $P<0.05$. This indicates the existence of significant positive relationship between cocuricular activities and academic achievement.

Table 4: Result of Hypothesis

\begin{tabular}{llll}
\hline Construct & Path Coefficient & T Value & P Values \\
\hline Cocurricular Activates $\rightarrow$ Academic Achievements & 0.620 & 8.396 & 0.000 \\
\hline
\end{tabular}

\section{CONCLUSION}

The research is conducted to find out that "How Co-curricular activities are useful to improve Academic Achievement". The research sample is taken from different Public and Private collages and from both genders. According to the result there are a positive relationship between Co-curricular activities and Academic Achievement. It mean that Co-curriular activities help students to improve there knowledge.

In Pakistan education system, promotes to get high score. In other words, it's better to say that here is a race to get high score rather than to be creative or to invent any new thing, to work on project. Cocurricular activities are not applied due to lack of education and narrow minded of students, teachers and parents because they think co-curricular activities are wastage of time. But co-curricular activities help students to in-hence their mental abilities, creatives and level of knowledge. Another major problem is lack of resources, finance and time. In our country we have limited resources and money in which students hardly complete their studies. If there may be any curricular or co-curricular activity in their institutes, most of them never that part because they have limited time to complete their course and low level of motivation.

According to all these factors there are some responsibility of Government, that they provide better resources and plate form to show their creativity and abilities. They have excellent ideas which help to improve the economic scale of Pakistan. The educational institutes motivate their students and guide them that how to do implement on their ideas and help them to complete their project and take then in national and international market. Provide students with better environment in which they can learned and give effective on results. Teachers should motivate their students because motivation is very important for any human to get excellent results.

\section{Reference:}

Adediwura, A. A. \& Tayo, T. (2007). Perceptions of teacher knowledge, attitude and teaching skills as predictor of academic performance in Nigerian secondary schools. Educational Research and Review, 2(7), 165-171.

Balls, 2008. Promoting excellence for all- School Improvement Strategy: raising standards, supporting schools. Nottingham, UK: DCSF.

Bektas F, Öcal MF 2012. School culture as the predictor of job satisfaction with respect to teachers' perceptions: A causal study. The New Educational Review, 27(1): 295-305.

Bhatti, M. N., Sami, A., \& Qureshi, I. (2018). Personality and academic performance among graduate students. Asia Proceedings of Social Sciences, 2(3), 256-259.

Blase, J. \& Blase, J. (1994). Empowering teachers: what successful principals do. Thousand Oaks, CA: Corwin Press, Inc.

Broh, B. A. (2002, January). Linking extracurricular programming to academic achievement: Who benefits and why? Sociology of Education, 75, 69-96.

Dimbisso, T. S. (2009). Understanding female students' academic performance: An exploration of the situation in South Nations nationalities and peoples' regional state - Ethiopia. A Research Paper Presented in Partial fulfillment of the Requirements for obtaining the degree of Master 
of Arts in Development Studies, International Institute of Social Science, The Hague, The Netherlands.

Erum Shahzadi and Zahoor Ahmad (2011), A Study on Academic Performance of University Students, Proc. 8th International Conference on Recent Advances in Statistics Lahore, Pakistan February 8-9, 2011, 255-268.

Fatih Bektas, Nazim Çogaltay, Engin Karadag and Yusuf Ay (2015), School Culture and Academic Achievement of Students: A Meta-analysis Study, Anthropologist, 21(3): 482-488 (2015).

Ghulam Rasool Memon (2007), Education in Pakistan: The Key Issues, Problems and The New Challenges, Journal of Management and Social Sciences Vol. 3, No. 1, (Spring 2007) 47-55.

Hanson, J.B. (2000). Student performance and student growth as measure of success: A evaluator's perspective. Paper presented at annual meeting of the American educational research association New Orleans. Louisiana. 25 April.

Kashif Rathore, Abdul Qayyum Chaudhry and Muhammad Azad (2018), Relationship between Cocurricular Activities and Exam Performance: Mediating Role of Attendance, Bulletin of Education and Research April 2018, Vol. 40, No. 1 pp. 183-196.

Khan, M.S. (2004). School curriculum. New Delhi: Ashish Publishing House.

Lewin, K. M., Wasanga, P., Wanderi, E. \& Somerset, A. (2011). Participation and Performance in Education in Sub-Saharan Africa with Special Reference to Kenya: Improving Policy and Practice. Create pathways to Access. Research Monograph No. 74: University of Sussex.

Newman, A., Thanacoody, R., Hui, W., 2011. The impact of employee perceptions of training on organizational commitment and turnover intentions: a study of multinationals in the Chinese service sector. Int. J. Hum. Resour. Manag. 22, 1765-1787.

Noe, R.A., Hollenbeck, J.R., Gerhart, B., Wright, P.M., 2006. Human resource management. China People's University Press.

Ostro, H. (2006). Should athletes be required to maintain a specific academic level? Coach and Athletic Director, 76(3), 16-17

Paul, A.K., Anantharaman, R.N., 2003. Impact of people management practices on organizational performance: Analysis of a causal model. Int. J. Hum. Resour. Manag.

Ramlall, S., 2003. Organizational application managing employee retention as a strategy for increasing organizational competitiveness. Appl. HRM Res. 8, 63-72.

Robert Freeman (2017), The Relationship between Extracurricular Activities and Academic Achievement, National Louis University Digital Commons@NLU, Dissertations. 245.

Sami, A., Jusoh, A., \& Qureshi, M. I. (2016). Does Ethical Leadership Create Public Value? Empirical Evidences from Banking Sector of Pakistan. International Review of Management and Marketing, 6(4S). 262-270

Simmons, A.B., Musoba, G.D. and Choong, C.G. (2005). Persistence Among First Generation College Students in Indiana: The Impact of Precollege Preparation, College Experiences, and Financial Aid. Indian Project on Academic Success (IPAS) Research Report \# 05-01.

Susan Lynn Smith (2007), The relationship between school culture and student Achievement in a large urban school district, The University of Southern Mississippi The Aquila Digital Community, Dissertations. 1291.

Tshewang Rabgay (2015), A Study of Factors Influencing Students' Academic Performance in a Higher Secondary School in Bhutan, Rabsel - the CERD Educational Journal Vol. 16, Issue - 2, Autumn 2015.

Wasal Khan and Mohammad Iqbal (2014), Role of Co-Curricular Activities in School Effectiveness, Middle East Journal of Scientific Research 21 (11): 2169-2176, 2014 ISSN 1990-9233 (C IDOSI Publications, 2014 DOI: 10.5829/idosi.mejsr.2014.21.11.21841.

Zahid Bashir (2012), The Effectiveness of Co-curricular Activities on Academic Achievements of Secondary School Students in District Abbottabad Pakistan - A Case Study, ISSN 2224-607X (Paper) ISSN 2225-0565 (Online) Vol 2, No.2, 2012. 